\title{
Proposta para abordagem de tópicos de Física Nuclear no ensino médio: análise de atividades com professores de Física em formação inicial ${ }^{+}$
}

Cleci Teresinha Werner da Rosa ${ }^{1}$

Universidade de Passo Fundo

Júpiter Cirilio da Roza da Silval

Universidade de Passo Fundo

Johnny Ferraz Dias ${ }^{1}$

Universidade Federal do Rio Grande do Sul

Porto Alegre - RS

Aline Locatelli ${ }^{1}$

Universidade de Passo Fundo

Passo Fundo - RS

\section{Resumo}

O estudo parte do entendimento da importância em abordar conteúdos de Física Nuclear, assim como os de Astronomia, no ensino médio, por meio da preparação dos professores em seus cursos de formação inicial. Nessa direção, o presente estudo buscou responder à seguinte pergunta: qual a viabilidade de uma proposta didática que toma o Calendário Cósmico como suporte de contextualização dos conteúdos de Física Nuclear presente no ensino médio? Dessa forma, o objetivo geral do trabalho situa-se na perspectiva de analisar como licenciandos de Física acolhem a associação da Física Nuclear com eventos astronômicos enquanto proposta de ensino voltada a melhorar a sua compreensão conceitual, bem como possibilidade didática para seu exercício profissional futuro. Para tanto, o estudo elegeu como sujeitos de investigação um curso de formação inicial de professores de Física para discutir tal possibilidade. A proposta didática, operacionalizada na forma de um curso de extensão, teve como instrumentos de avaliação junto ao público investigado o uso de dois questionários, um aplicado no

\footnotetext{
${ }^{+}$Proposal to approach Nuclear Physics topics in high school: analysis of activities with physics teachers in pre-service

* Recebido: junho de 2020 Aceito: julho de 2020.

1E-mails: cwerner@upf.br; 135313@upf.br; jfdias@if.ufrgs.br; alinelocatelli@upf.br
} 
início das atividades e outro ao final. De forma geral, os resultados apontaram que os acadêmicos se envolveram com as atividades desenvolvidas, manifestando ampliação de seus conhecimentos no campo da Física Nuclear constatada por meio das respostas analisadas nos dois questionários aplicados.

Palavras-chave: Calendário Cósmico; Ensino Médio; Proposta Didática.

\begin{abstract}
The present work deals with the importance of approaching Nuclear Physics and Astronomy contents in High School by means of appropriate education of teachers in their initial graduation courses. The key question of the present research is: Is it possible to teach nuclear physics in the framework of the cosmic calendar for high school students? The goal of this work is to perform an analysis of how physics academics welcome the teaching of nuclear physics embedded within astronomical events for teaching high school students. To that end, the present research elected as the subject of investigation a course of initial training of teachers of Physics to discuss such possibility. The proposal was devised as in the an extension course making use of pre-and postquestionnaires with the audience. In general, the results showed that the academics involved themselves with the developed activities, showing improvement of their knowledge about Nuclear Physics verified through the answers given to appropriate questionnaires.
\end{abstract}

Keywords: Cosmic Calendar; High School; Pedagogical Proposal.

\title{
I. Introdução
}

De acordo com Gleser (2006) o estudo dos acontecimentos celestes é tema instigante para a humanidade. Situação que também pode ser percebida nos Planetários sempre repletos de estudantes curiosos e fascinados pela observação do céu. Assim como a Astronomia, a Física Nuclear também tem despertado interesse e curiosidade dos estudantes, particularmente daqueles que estão no ensino médio, embora sua presença ainda seja pequena nos currículos (ROSA, 2001). Além de interessante, Souza (2010) relata que ela tem "papel de destaque no cenário científico atual, e até mesmo na política econômica internacional no que concerne ao enriquecimento de urânio para fins militares ou produção de energia elétrica, o que a torna um assunto relevante do ponto de vista educacional" (p. 138-139). 
Tal identificação não representa uma novidade, uma vez que os próprios Parâmetros Curriculares Nacionais - PCN (BRASIL, 2002) já estruturaram os eixos temáticos para o componente Física de modo a contemplar esses tópicos, sob a justificativa de que estão presentes na vida cotidiana desses estudantes. A Base Nacional Curricular Comum - BNCC (BRASIL, 2018) continuou na mesma linha apontando a necessidade de que ao final do ensino médio os estudantes tenham desenvolvidos competências e habilidades que estão associadas a esses conteúdos.

No caso do documento mencionado e em se tratando da Física Nuclear (FN), identificamos a presença desses conteúdos em diferentes passagens do texto, especificamente, em termos das competências que devem ser desenvolvidas nos alunos. Dentre as passagens presentes na BNCC temos a de que os estudantes ao final do ensino médio devem ter condições de "analisar fenômenos naturais e processos tecnológicos, com base nas relações entre matéria e energia, para propor ações individuais e coletivas que aperfeiçoem processos produtivos, minimizem impactos socioambientais e melhorem as condições" (BRASIL, 2018, p. 540). Portanto, temos a indicação de que a área de Ciências deve abarcar conteúdos associados a estabelecer relações entre "matéria e energia, possibilitando, por exemplo, a avaliação de potencialidades e de limites e riscos do uso de diferentes materiais e/ou tecnologias para tomar decisões responsáveis e consistentes diante dos diversos desafios contemporâneos" (BRASIL, 2018, p. 540).

Esses são exemplos que revelam a necessidade de que nos cursos de formação de professores, tenhamos um olhar para os conteúdos específicos de cada curso, mas ao mesmo tempo para questões que permitam que esses conteúdos se tornem objeto de ensino junto ao público alvo que, neste caso, seriam os professores do ensino médio. Embora tenhamos nas licenciaturas essa preocupação, o que queremos chamar a atenção aqui é que a preparação para ser professor não pode estar dissociada da apropriação dos conteúdos específicos de Física. Desta maneira, nossa proposta é que diante do apresentado na BNCC posamos ter alternativas didáticas que, ao discutir os conhecimentos, mostram aos futuros professores alternativas para sua operacionalização no ensino médio. Isso possibilita ultrapassar a dissociação entre as disciplinas específicas e as voltadas ao exercício profissional futuro, realidade presente nas universidades e centros de formação de professores no Brasil.

Diante da problemática que tem se revelado presente na formação dos professores, estabelecemos como recorte do presente estudo, estudar a pertinência de uma proposta didática desenhada de modo a favorecer a apropriação dos conhecimentos em FN necessários a um professor de Física, bem como estrutura-la dentro de uma proposta que possa ser levada ao ensino médio. Para tanto, tomamos como subsídio teórico a discussão de contextualização dos saberes, inferindo uma proposta didática em que a FN é discutida a partir do Calendário Cósmico (CC), na forma como proposto por Carl Sagan (1934-1996), no livro Os Dragões do Éden e, posteriormente, apresentado na série televisiva Cosmo, exibida na década de 1980. 
Para tanto, com base no desejo de um processo que favoreça a formação de futuros professores críticos e atuantes na sociedade contemporânea, ao mesmo tempo em que possam favorecer o mesmo a seus futuros alunos, inferimos a seguinte questão como central no estudo: Qual a viabilidade de uma proposta didática que toma o Calendário Cósmico como suporte contextualizador dos conteúdos de Física Nuclear presente no ensino médio?

Tal questionamento, formulado com a intencionalidade de estabelecer diálogos entre a Astronomia e a FN, que integram os conteúdos de Física no ensino médio, levou a investigar a sua pertinência em termos conceituais e didáticos. Nesse sentido, o estudo estabeleceu como sujeito de investigação um grupo de futuros professores de Física, a fim de que analisassem a proposta didática elaborada em termos das contribuições para a apropriação dos conceitos e como estratégia didática. Em outras palavras, selecionamos um grupo de sujeitos que não teve contato com o conteúdo de FN, por não fazer parte de sua formação, mas que está na iminência de ser professor e, portanto, e em tese, capacitado para uma análise didática.

Sobre a presença de disciplinas de FN nos cursos de formação inicial de professores de Física destacamos que, em uma análise das grades curriculares dos cursos no estado do Rio Grande do Sul, identificamos que, em um universo de 20 cursos entre presenciais e Ensino à Distância $(\mathrm{EaD})$ de licenciatura em Física, apenas três apresentam uma disciplina específica voltada a esse campo de conhecimentos ${ }^{2}$. Nos demais cursos, esta área está incluída em disciplinas relacionadas, por exemplo, à Física Moderna e à Estrutura da Matéria. Embora não seja o foco do presente estudo, é importante destacar que tal identificação remete a uma análise mais aprofundada como forma de repensar a formação inicial dos professores de Física, uma vez que esse tópico integra a lista dos conteúdos do ensino médio no componente curricular da Física.

A importância de estudar a FN no ensino médio reside no fato de sua contribuição para a alfabetização científica dos jovens, fornecendo elementos para que compreendam e dialoguem com o mundo em que vivem. Além disso, sua importância está associada ao fato de que ela se revela presente em diversas áreas que fazem parte do cotidiano dos alunos, como medicina, indústria, agricultura e produção de energia. Além disso, os conhecimentos nesse campo se mostram essenciais quando se trata dos perigos que a manipulação de equipamentos e dispositivos atrelados a eles podem ocasionar quando não se tem conhecimentos mínimos na área, situação evidenciada em acidentes nucleares como o de Chernobyl, em 1986, e o de Goiânia, em 1987, assim como podemos mencionar as corridas armamentistas em busca do aperfeiçoamento da bomba atômica após o término da Segunda Guerra Mundial, em 1945.

Outro momento que podemos mencionar, e mais recente, é no Japão em 2011. Sendo o último acidente radiológico registrado até então, o país insular foi abalado no início de 2011

\footnotetext{
${ }^{2}$ Os dados referentes aos cursos de licenciatura em Física no estado do Rio Grande do Sul foram obtidos na página do Ministério da Educação (MEC) (http://emec.mec.gov.br/). A partir da identificação dos cursos, buscou-se, nas páginas institucionais das respectivas universidades, as grades curriculares e ementa das disciplinas.
} 
por um maremoto causado por um deslocamento de placas tectônicas ocorrido em alto mar. Este maremoto por sua vez deu a origem a um tsunami que acabou por atingir a usina de Fukushima. Este fenômeno foi responsável por danificar o sistema de resfriamento da usina e contribuir para a proliferação de material radioativo. Junto com Chernobyl, o acidente nuclear em Fukushima também é considerado um dos piores já ocorridos e o segundo a chegar a nota 7 na escala de acidentes nucleares. Mas devido a competência das autoridades e aos protocolos de segurança seguidos, as consequências do acidente foram mínimas em comparação à Chernobyl.

Esses são exemplos que ilustram a importância de abordar a FN no ensino médio e que tem se revelado um problema a partir da identificação de que ela tem sido pouco contemplada nesse nível de escolarização. Outro estudo que corrobora que a FN tem sido pouco explorada no ensino médio foi o desenvolvido por Souza (2018). O autor propõe uma sequência didática para ser abordada no ensino médio no qual o tema central é a FN, recorrendo a diferentes instrumentos didáticos (textos, filmes, vídeos, figuras, atividades experimentais e outros) como forma de verificar a aceitação dos alunos frente a esse tema e a estrutura didática proposta. Como justificativa o autor menciona os poucos estudos envolvendo atividades didáticas na temática FN no ensino médio. Como conclusão do seu estudo Souza (2018) relata os resultados acadêmicos positivos expressos pelas avaliações somativas realizadas após o desenvolvimento das atividades e pela contribuição das discussões realizadas "para a formação de um cidadão consciente e participativo, que atue nesse mundo" (p. 87).

Tendo como pano de fundo o que foi mencionado, inferimos que o objetivo do estudo é analisar como licenciandos de Física acolhem a associação da FN com eventos astronômicos enquanto proposta de ensino voltada a melhorar a sua compreensão conceitual.

A partir do apresentado e tomando como referencial a necessidade de dialogar com futuros professores, adotamos uma pesquisa qualitativa, apoiada no uso de dois questionários (um no início das atividades e outro ao final) como forma de discutir as contribuições para a apropriação dos conceitos associados à FN. Os resultados foram analisados à luz do referencial construído e buscam responder ao questionamento principal desta pesquisa.

\section{Material elaborado e atividades desenvolvidas}

Para o desenvolvimento do estudo foi estruturada uma proposta didática que tomou como inspiração o Calendário Cósmico (CC) cuja concepção inicial foi de representar a idade do Universo, em sua totalidade, na forma de um calendário. Essa é uma tentativa didática de abordar o Universo dentro de uma escala de uso cotidiano, cujo ponto de partida foi o calendário Gregoriano e, assim, a idade do Universo fica estruturada em 12 meses, com 365 dias. Ou seja, cerca de 13,8 bilhões de anos ficam divididos em 12 partes. Dentro desta escala, o mês possui aproximadamente 1,2 bilhões de anos, o dia em torno de 38 milhões de anos e um segundo de tempo é equivalente a 438 anos. Nessa abordagem, toda a produção de 
conhecimento que o ser humano produziu nos últimos $10 \mathrm{mil}$ anos aconteceu em aproximadamente 23 segundos. O calendário tem início em primeiro de janeiro, com o Big Bang, e termina em 31 de dezembro, o que corresponde à atualidade.

Nessa escala, no dia primeiro de janeiro, à zero hora, ocorre o Big Bang e, com isso, o Universo surge a partir de uma grande expansão. As primeiras estrelas aparecem quase no término da segunda semana de janeiro e a Via Láctea começa a se formar na última semana do mesmo mês, tomando a forma final em meados de maio. Na primeira semana de setembro o Sistema Solar é formado, e na semana seguinte a Terra. A vida começa no primeiro dia de outubro. Os dinossauros aparecem e são extintos na mesma semana, ou seja, a última de dezembro. A aparição do homem fica reservada para o dia de 31 de dezembro, em torno das 21 horas. Os últimos 12 segundos do último dia do ano representam 6 mil anos e comportam toda a história registrada da humanidade.

$\mathrm{O}$ calendário tem a potencialidade de colocar à discussão diversas áreas, como a Cosmologia, a Astrofísica, a Astronomia e, claro, a FN. A FN é abordada, especialmente, em três momentos distintos: durante a nucleossíntese estelar, que ocorre através do processo de fusão nuclear; a estimativa da idade da Terra pela datação radioativa; e a criação das bombas nucleares a partir do princípio da fissão nuclear. Respeitando a cronologia dos fatos, o material iniciou pela discussão sobre as origens do Universo e das partículas subatômicas, as primeiras porções de átomos e das estrelas. Na sequência, aborda as galáxias, a origem do Sol, os planetas e a Terra, a vida, as eras e os períodos. O desfecho disso são os últimos 12 segundos do calendário, momento em que são retratadas as primeiras comunidades. Nesse tempo, são adicionados os primeiros conhecimentos envolvendo a Astronomia e descritos o período antigo com os gregos, a idade medieval e a época renascentista. Ainda, são inseridos a idade moderna, com as revoluções filosóficas, sociais e científicas, e os dias atuais, com a informática e a tecnologia.

Os eventos identificados no $\mathrm{CC}$ e que serviram de referência para as discussões sobre FN estão representados no Quadro 1, a seguir.

Quadro 1 - Eventos destacados do CC.

\begin{tabular}{|c|c|c|c|}
\hline Mês & Dia & Hora & Evento \\
\hline \multirow{4}{*}{ Janeiro } & 01 & 00 hora, 00 minuto, 00 segundo & Big Bang \\
\cline { 2 - 4 } & 12 & 17 horas, 44 minutos, 46 segundos & Primeiras estrelas \\
\cline { 2 - 4 } & 26 & 10 horas, 55 minutos, 14 segundos & Primeiras galáxias \\
\hline \multirow{3}{*}{ Setembro } & 02 & 05 horas, 56 minutos, 48 segundos & Formação do Sistema Solar \\
\cline { 2 - 4 } & 05 & 10 horas, 24 minutos, 25 segundos & Formação dos planetas \\
\cline { 2 - 4 } & 08 & 02 horas, 07 minutos, 26 segundos & Formação da Lua \\
\hline Outubro & 01 & 10 horas, 49 minutos, 54 segundos & Origem da vida \\
\hline \multirow{3}{*}{ Dezembro } & 06 & 19 horas, 45 minutos, 07 segundos & Primeiros seres complexos \\
\cline { 2 - 4 } & 31 & 06 horas, 00 minuto, 00 segundo & Primeiros macacos \\
\cline { 2 - 4 } & & 21 horas, 00 minuto, 00 segundo & Primeiros hominídeos \\
\hline
\end{tabular}




\begin{tabular}{|c|c|c|c|}
\hline & & 23 horas, 59 minutos, 00 segundo & Pré-história \\
\hline & & 23 horas, 59 minutos, 48 segundos & Nascimento da astronomia \\
\hline & & 23 horas, 59 minutos, 54 segundos & Antiguidade \\
\hline & & 23 horas, 59 minutos, 59 segundos & Idade moderna \\
\hline & & $\begin{array}{l}23 \text { horas, } 59 \text { minutos, } 59 \text { segundos e } 83 \\
\text { centésimos de segundo }\end{array}$ & Idade contemporânea \\
\hline
\end{tabular}

Fonte: pesquisa (2018).

Os eventos destacados no Quadro 1 representam pontos que guiam a viagem pelo $\mathrm{CC}$ e a colocação no quadro visa explicitar a escala de tempo de um evento para o outro. No primeiro momento com a formação da matéria mais simples e depois mais complexa (Big Bang - Estrelas). No próximo, as suas interações (Primeiras galáxias - Sistema Solar). Na continuidade, o aumento da complexidade (Origem da vida) e, por fim, a própria civilização (nascimento da astronomia).

A atividade desenvolvida com os professores de Física em formação inicial ocorreu na forma de curso de extensão, denominado "Calendário Cósmico e Física Nuclear", e foi estruturado em quatro encontros presenciais, perfazendo um total de 16 horas/aula. O Quadro 2 ilustra os tópicos contemplados em cada encontro e que integram o material didático elaborado especialmente para o presente estudo.

Quadro 2 - Descrição das atividades realizadas no curso de extensão.

\begin{tabular}{|c|c|l|}
\hline Encontro & Horas-aula $^{3}$ & \multicolumn{1}{c|}{ Atividade } \\
\hline 1 & 4 & $\begin{array}{l}\text { Aplicação do questionário inicial -conhecimentos prévios; } \\
\text { Questionamentos iniciais; } \\
\text { Introdução à FN - aspectos históricos; Resgate de conhecimentos em } \\
\text { Astronomia; Apresentação do Calendário Cósmico; Nucleossíntese primordial. }\end{array}$ \\
\hline 2 & 4 & $\begin{array}{l}\text { Radiação cósmica de fundo; Era da recombinação; Primeiras estrelas Formação } \\
\text { estelar; Fator: Massa; Fusão nuclear; Evolução estelar; Morte das estrelas; } \\
\text { Radiação Hawking. }\end{array}$ \\
\hline 3 & 4 & $\begin{array}{l}\text { Formação do Sistema Solar; Sol - A nossa estrela; Componentes do Sistema } \\
\text { Solar; Formação da Terra; Formação da Lua; Datação radioativa; } \\
\text { Elementos radioativos; Origem da Radioatividade; Interação nuclear; } \\
\text { Decaimentos radioativos; Meia-vida. }\end{array}$ \\
\hline 4 & 4 & $\begin{array}{l}\text { Formação da vida; Evolução biológica; Eras geológicas; Astronomia e ciência } \\
\text { moderna; Radioatividade artificial; Fissão nuclear; Bombas atômicas; } \\
\text { Acidentes radiológicos; Protocolos de segurança; Aplicações da FN; } \\
\text { Realização do questionário final. }\end{array}$ \\
\hline
\end{tabular}

Fonte: pesquisa (2018)

\footnotetext{
${ }^{3}$ Cada hora-aula corresponde a 50 minutos, porém para efeitos de certificado contabiliza-se uma hora-aula como uma hora-relógio.
} 
O descrito no Quadro 2 caracteriza as atividades realizadas no estudo, cuja caracterização dos sujeitos e local de desenvolvimento da investigação são apresentadas na próxima seção.

\section{Pesquisa}

A pesquisa desenvolvida classifica-se como de natureza qualitativa cuja opção decorre da busca por analisar e compreender os fenômenos a partir de uma avaliação mais global, sem se prender a dados estatísticos (TRIVIÑOS, 1987). A ênfase está em identificar as peculiaridades e experiências individuais dos sujeitos investigados.

Como sujeitos de pesquisa, foram convidados a participar do curso de extensão mencionado na seção anterior, acadêmicos de um curso de licenciatura em Física de uma universidade localizada no interior do Rio Grande do Sul. Por livre adesão e sendo informado sobre a pesquisa em desenvolvimento, participaram do estudo um grupo de acadêmicos que variou de 15 sujeitos no primeiro encontro a nove no último encontro.

Como instrumentos para coleta de dados e análise das contribuições da atividade para ampliação conceitual dos professores de Física em formação inicial, recorremos ao uso de dois questionários, sendo um no início das atividades (conhecimentos prévios) e outro ao final (conhecidos adquiridos). Os questionários foram constituídos por perguntas abertas sobre os temas FN e Astronomia e foram aplicados em dois momentos distintos: o questionário inicial no primeiro encontro, no início das atividades e questionário final no quarto encontro, como última atividade. Tais testes são similares, uma vez que buscam analisar a pertinência em termos didáticos e da apropriação e ampliação do conhecimento.

\section{Resultados e discussões}

Como forma de avaliar a viabilidade da proposta em termos da compreensão conceitual, analisaremos as respostas dos acadêmicos aos questionários realizados no primeiro e no último encontro. O questionário realizado na etapa inicial se distingue do realizado na última etapa, uma vez que o objetivo do primeiro era identificar os conhecimentos prévios dos participantes e o do segundo verificar os adquiridos. Embora as perguntas nos dois testes possam ser consideradas como equivalentes ou próximas, elas foram estruturadas de forma diferenciadas entre si. As exceções, por conta da equivalência nas perguntas, são as questões de número 2 do questionário inicial de número 7 do questionário final, que contêm caráter exclusivo e, portanto, são analisadas separadamente. As questões foram elaboradas pelos autores a partir dos tópicos contemplados no curso.

O questionário inicial foi respondido por 15 acadêmicos e o questionário final por nove. Considerando que as questões eram subjetivas, decidimos apresentar os resultados e as análises entre os dois questionários. Ou seja, a análise é feita com base em um comparativo entre as respostas coletadas nos dois testes. Para isso, entendendo que as perguntas eram 
distintas, embora equivalentes, recorremos a quadros como forma de possibilitar a visualização das respostas obtidas em cada umas das questões. Na sequência de cada quadro, são realizadas as respectivas análises.

O quadro 3, a seguir, é composto, inicialmente, pela questão do questionário inicial, tendo, ao lado, as respostas obtidas. $\mathrm{O}$ mesmo ocorre com a questão do questionário final e suas respectivas respostas. $\mathrm{O}$ termo entre parênteses indica a repetição da resposta pelos licenciandos.

Quadro 3 - Questão 1 do questionário inicial e 2 do questionário final com as respectivas respostas.

\begin{tabular}{|c|c|}
\hline $\begin{array}{l}\text { QUESTIONÁRIO } \\
\text { INICIAL }\end{array}$ & RESPOSTAS \\
\hline $\begin{array}{l}\text { Qual é a origem da } \\
\text { energia do Sol? }\end{array}$ & $\begin{array}{l}\text { "Fusões nucleares"; "Entropia"; "Com a fissão nuclear dos elementos leves para } \\
\text { mais pesados"; "A transformação de hidrogênio e hélio"; "Pela fusão nuclear do } \\
\text { hidrogênio e do hélio"; "Fusão nuclear } \rightarrow \text { hidrogênio em hélio"; "Interação entre } \\
\text { as partículas subatômicas"; "Fissão nuclear. Quebra do átomo de He em He } \\
\text { energia liberada"; "Por meio de fusão nuclear dos átomos de H, a qual libera } \\
\text { energia"; Em branco (1). }\end{array}$ \\
\hline $\begin{array}{c}\text { QUESTIONÁRIO } \\
\text { FINAL }\end{array}$ & RESPOSTAS \\
\hline $\begin{array}{l}\text { Qual a origem da } \\
\text { energia derivada do } \\
\text { processo de fusão } \\
\text { nuclear? }\end{array}$ & $\begin{array}{l}\text { "Radiação"; "Do colapso gravitacional, no caso, do núcleo das estrelas"; "A partir } \\
\text { da divisão do núcleo atômico num processo de fissão nuclear"; "Energia nuclear"; } \\
\text { "A colisão entre dois núcleos gera um novo elemento e nesse processo ocorre uma } \\
\text { 'sobra' de energia"; "É da união de dois elementos quimicos que libera muita } \\
\text { energia"; "Radioativa"; "A quebra do átomo e liberação de energia residual"; Em } \\
\text { branco (1). }\end{array}$ \\
\hline
\end{tabular}

Fonte: dados da pesquisa, 2018.

O objetivo da questão do questionário inicial era esclarecer se os licenciandos tinham a noção do fenômeno da fusão nuclear e o conhecimento da sua ocorrência dentro do núcleo das estrelas. Enquanto isso, a questão do questionário final teve como propósito verificar se havia clareza do processo. Quanto às respostas do questionário inicial, podemos perceber que os estudantes apresentaram conhecimento sobre o fenômeno da fusão nuclear, considerando o número de respostas corretas, o que não é percebido no questionário inicial, pois, atentando às respostas obtidas, os alunos mostraram pouco conhecimento sobre o processo. Um conceito que ficou evidenciado no questionário inicial foi o de "defeito de massa" (OLIVEIRA FILHO; SARAIVA, 2014), o qual dá origem à energia do processo. No questionário final, o mesmo não ficou evidente.

Este ponto foi abordado no segundo encontro, quando tratamos do nascimento das estrelas dentro do CC. Nele, foi mencionado o fator da massa como sendo um componente 
importante para uma estrela, podendo definir seu tempo de vida, luminosidade, desfecho de vida e outras características. Nesse encontro, como forma de ilustrar o debate, foi realizado um exercício para calcular o quanto de energia é possível ter no processo de fusão de um próton-próton, que é a fusão primária que acontece no meio estelar. Na sequência, foram utilizadas relações simples para determinar o tempo de vida de uma estrela com uma massa solar.

Quadro 4 - Questão 2 do questionário inicial com as respostas.

\begin{tabular}{|c|c|}
\hline $\begin{array}{l}\text { QUESTIONÁRIO } \\
\text { INICIAL }\end{array}$ & RESPOSTAS \\
\hline $\begin{array}{l}\text { Qual o processo que } \\
\text { se realiza em usinas } \\
\text { termelétrica para se } \\
\text { obter energia? }\end{array}$ & $\begin{array}{l}\text { "Não sei explicar, mas acredito que há uma troca de calor que gera uma atividade } \\
\text { mecânica"; "Queima de combustivel para ebulir a água"; "Queima-se materiais } \\
\text { inflamáveis, como carvão e madeira, e através de uma caldeira, ferve-se água que } \\
\text { gira um eletroímãa que gera eletricidade"; "Usa-se algum processo térmico de } \\
\text { geração de calor para aquecer a água e, assim, o vapor, sob pressão, move as } \\
\text { turbinas"; "Também fusão nuclear, porém de átomos mais instáveis"; Em branco } \\
\text { (5). }\end{array}$ \\
\hline
\end{tabular}

Fonte: dados da pesquisa, 2018.

A segunda questão do questionário inicial, expressa no quadro 5, não equivalente no questionário final, teve o objetivo de verificar se os licenciandos apresentavam algum conhecimento sobre fissão nuclear, bem como acerca da produção de energia, cujo processo é comum em países como a França, onde $75 \%$ da sua energia tem origem (GONÇALVES; ALMEIDA, 2005).

Os resultados obtidos no questionário inicial demonstram que os acadêmicos entendem que, para geração de energia nas usinas termelétricas, é utilizada a ebulição da água, que passa por turbinas e, depois, por geradores. Todavia, não está presente nas respostas a origem do calor para a ebulição, o qual utiliza, em alguns casos, a fisssão nuclear. Esse tema foi assunto do quarto e último encontro, momento em que foram apresentados aos alunos a fissão nuclear, sua origem e aplicações, como nas bombas atômicas e nas usinas, e casos como os acidentes radiológicos.

Quadro 5 - Questão 3 do questionário inicial e do questionário final com as respectivas respostas.

\begin{tabular}{|l|l|}
\hline \multicolumn{1}{|c|}{$\begin{array}{l}\text { QUESTIONÁRIO } \\
\text { INICIAL }\end{array}$} & \multicolumn{1}{c|}{ RESPOSTAS } \\
\hline $\begin{array}{l}\text { Caracterize os } \\
\text { diferentes tipos de } \\
\text { radiação }\end{array}$ & $\begin{array}{l}\text { "Radiação térmica e nuclear"; "Radiação alfa, beta, gama/associada a energia } \\
\text { transportada pela onda"; "Alfa, beta e gama"; "Raio x, infravermelho, luz visivel, } \\
\text { ultravioleta, rádio"; "Radiação térmica, radiação Hawking"; "Radiação térmica } \\
\text { (emissão de ondas de calor), radiação nuclear (emitida pelo decaimento atômico)"; }\end{array}$ \\
\hline
\end{tabular}




\begin{tabular}{|c|c|}
\hline & "Eletromagnética, térmica, luminosa, gama, alfa, beta, Hawking”; Em branco (3). \\
\hline $\begin{array}{c}\text { QUESTIONÁRIO } \\
\text { FINAL }\end{array}$ & RESPOSTAS \\
\hline $\begin{array}{l}\text { Quais os possíveis } \\
\text { tipos de radiação que } \\
\text { um elemento pode } \\
\text { emitir? }\end{array}$ & "Alfa, beta, gama” (7); "Alfa, beta, gama e Hawking” (2); "Sei lá” (1). \\
\hline
\end{tabular}

Fonte: dados da pesquisa, 2018.

A questão 3 do questionário inicial, apresentada no quadro 5, buscou identificar se os licenciandos apresentavam discernimento quanto às peculiaridades de cada radiação, como a alfa, composta por dois prótons e dois nêutrons (ou também ${ }^{4} \mathrm{He}$ ), ou a gama, considerada uma onda eletromagnética. As respostas apontam que os participantes mostravam conhecimentos sobre a questão, não havendo alteração significativa de conhecimento, conforme revelado no questionário final.

Sobre isso, precisamos expor que a menção à radiação Hawking, tanto no questionário inicial, como no final, pode estar relacionada a uma atividade realizada pelos licenciandos na semana anterior a aplicação do questionário inicial, numa palestra realizada na semana Acadêmica, ou ao falecimento do físico Stephen Hawking (1942-2018), em 2018, que levou a mídia a divulgar muitos de seus trabalhos, especificamente, os vinculados a buracos negros e à radiação Hawking. Tais episódios podem ter contribuído para as respostas fornecidas pelos licenciandos, especialmente, no questionário inicial.

Quadro 6 - Questão 4 do questionário inicial e do questionário final com as respectivas respostas.

\begin{tabular}{|c|c|}
\hline $\begin{array}{c}\text { QUESTIONÁRIO } \\
\text { INICIAL }\end{array}$ & RESPOSTAS \\
\hline $\begin{array}{l}\text { O que caracteriza um } \\
\text { elemento químico } \\
\text { como radioativo? }\end{array}$ & $\begin{array}{l}\text { "Quando este apresenta caráter instável, isto é, quando 'facilmente' mutar-se em } \\
\text { outro elemento químico", "Quantidade de elétrons livros e instabilidade do átomo"; } \\
\text { "A emissão de partículas radioativas (alfa, beta e gama)", "Seus átomos são } \\
\text { instáveis e sua cama decai com o tempo emitindo radiação"; "Quando é modificado } \\
\text { o núcleo, causando uma liberação de energia"; "Quando ele ter um número atômico } \\
\text { muito alto"; "Ser instável, ter um número atômico alto, uma certa vida' e ser um } \\
\text { grande emissor de partículas"; "Ser instável a ponto de decompor-se, gerando outros } \\
\text { elementos e emitindo radiação",; Em branco (2). }\end{array}$ \\
\hline $\begin{array}{l}\text { QUESTIONÁRIO } \\
\text { FINAL }\end{array}$ & RESPOSTAS \\
\hline
\end{tabular}




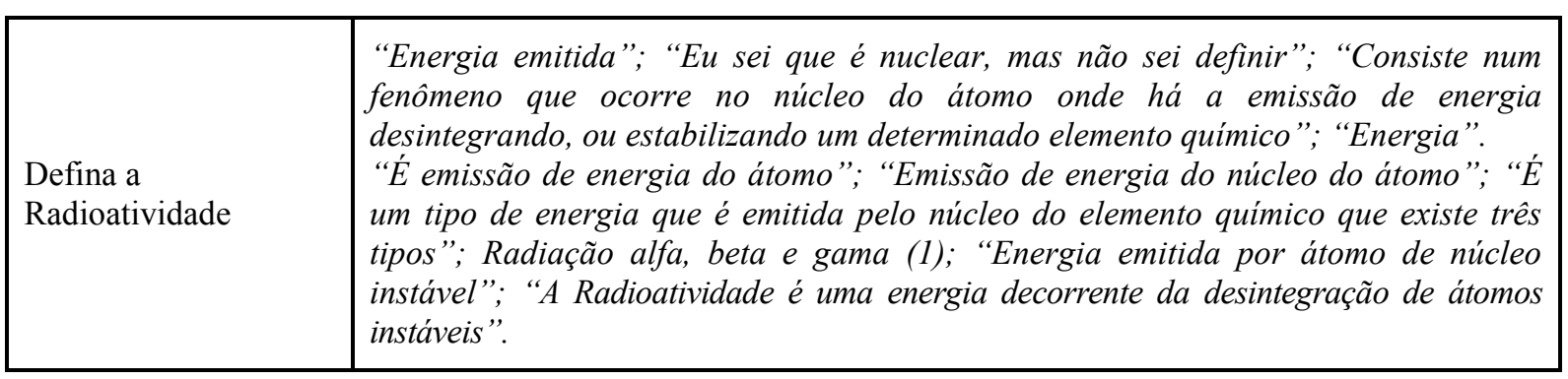

Fonte: dados da pesquisa, 2018.

O quadro 6 apresenta as respostas dadas à quarta questão, cujo objetivo era buscar elementos que evidenciassem nas respostas a questão da instabilidade nuclear. Dadas as respostas, constatamos que a noção de elementos radioativos estava mais ligada a uma transmutação com liberação de radiação do que ao núcleo atômico instável. Este tema foi tratado durante o terceiro encontro, quando exploramos a idade da Terra, discutindo o processo de datação por meios radioativos. No encontro, foi definido o conceito de radioatividade como sendo um modo encontrado pelo átomo para se tornar estável, isto é, uma maneira de se desfazer de uma porção de energia (sendo em forma de partículas ou em ondas eletromagnéticas) e assim encontrando um equilíbrio entre as forças que agem sobre o núcleo. Chamamos de "radiação" a energia produzida pelo núcleo atômico, podendo ser de três maneiras, ou três tipos: a radiação alfa, beta e gama, sendo que para cada radiação existe uma característica específica.

Nas respostas do questionário final, percebemos uma pequena diferença em relação ao apresentado no questionário inicial, especificamente em relação à menção de "instabilidade nuclear". Foi mencionado que o processo ocorreu com a datação de um fragmento de zircão de 4,3 bilhões de anos, estimativa em virtude da presença de isótopos de urânio (U-238 e U235) e tório (Th-232), dois elementos radioativos encontrados junto ao mineral zircão. Em função da presença destes dois elementos (3 isótopos: U-238, U-235, Th-232) e de acordo com o seu longo período de decaimento radioativo, o resultado final será a existência de dois isótopos de chumbo, $\mathrm{Pb}-206$ e Pb-207 junto ao fragmento de zircão. A instabilidade nuclear foi explicada a partir da interação nuclear, do méson pi e do seu alcance limitado, definindo a radioatividade.

Quadro 7 - Questão 5 do questionário inicial e 6 do questionário final com as respectivas respostas.

\begin{tabular}{|l|l|}
\hline QUESTIONÁRIO INICIAL & RESPOSTAS \\
\hline $\begin{array}{l}\text { Cite diferentes partículas subatômicas e, se } \\
\text { possível, aponte as suas diferenças (carga, spin, } \\
\text { formação, interação). }\end{array}$ & $\begin{array}{l}\text { Prótons (7); Elétrons (7); Nêutrons (8); Pósitrons (1); } \\
\text { Antiprótons (1); Neutrinos (2); Grávitons (1); Quarks (7); } \\
\text { Bósons (3); Mésons (1); Corda (1); Tau (1). Em branco } \\
\text { (1). }\end{array}$ \\
\hline
\end{tabular}




\begin{tabular}{|l|l|}
\hline QUESTIONÁRIO FINAL & RESPOSTAS \\
\hline $\begin{array}{l}\text { Cite algumas partículas elementares, isto é, sem } \\
\text { estrutura interna. }\end{array}$ & $\begin{array}{l}\text { Quark (7); Elétron (1); Bárions (2); Mésons (2); Gluons } \\
\text { (1); Não sei (1); Em branco (1). }\end{array}$ \\
\hline
\end{tabular}

Fonte: dados da pesquisa, 2018.

Como mostrado no quadro 7 , as partículas mais conhecidas - próton, nêutron e elétron - foram as mais citadas no questionário inicial, sendo também mencionado o quark. Entretanto, percebemos que essas menções foram aleatórias, sem critérios, enquanto, no questionário final, podemos identificar a existência de respostas criteriosas. Todavia, identificamos um equívoco nas menções aos bárions e mésons como partículas sem estrutura interna.

O tema foi tratado logo no primeiro encontro, no início da jornada pelo $\mathrm{CC}$, quando excursionamos pelas primeiras eras. Logo após o Big Bang, temos a separação das forças elementares e, posteriormente, a formação da matéria. Ainda nesse encontro, foram relatados a primeira era, a de Planck, e o primeiro momento quando o Universo começa a ser estruturado. Ainda, mencionamos a gravidade como a primeira força elementar a se separar das outras, a força forte, a força fraca e o eletromagnetismo. Iniciando a era Quark, destacamos o início da formação da matéria elementar. Depois, a era Hadrônica, com estruturas um pouco maiores. Por fim, a era Leptonica, com as partículas que não experimentam a força nuclear forte. Em cada momento, foram discutidas as partículas e suas especificidades.

Quadro 8 - Questão 6 do questionário inicial e 5 do questionário final com as respectivas respostas.

\begin{tabular}{|c|c|}
\hline $\begin{array}{l}\text { QUESTIONÁRIO } \\
\text { INICIAL }\end{array}$ & RESPOSTAS \\
\hline $\begin{array}{l}\text { No Universo, existem } \\
\text { quatro interações } \\
\text { fundamentais, aponte } \\
\text { quais são e as descreva. }\end{array}$ & $\begin{array}{l}\text { Força nuclear forte (7); Força nuclear fraca (7); Força gravitacional (6); Força } \\
\text { eletromagnética (7); Em branco (3). }\end{array}$ \\
\hline $\begin{array}{l}\text { QUESTIONÁRIO } \\
\text { FINAL }\end{array}$ & RESPOSTAS \\
\hline $\begin{array}{l}\text { Como podemos explicar } \\
\text { a interação que mantém o } \\
\text { núcleo atômico coeso? }\end{array}$ & $\begin{array}{l}\text { "Troca de particulas"; "A força nuclear ocorre devido a interação entre prótons } \\
\text { e nêutrons"; "Através da força forte, uma força maior, mais intensa que a } \\
\text { eletromagnética"; "Energia nuclear forte"; "É a energia nuclear forte, onde faz } \\
\text { com que a interação do próton faz com as outras partículas", "Interação entre os } \\
\text { mésons Pi"; "É através da força forte que faz a ligação entre os prótons e os } \\
\text { nêutrons"; "Nuclear forte"; Núcleo atômico (1). }\end{array}$ \\
\hline
\end{tabular}

Fonte: dados da pesquisa, 2018. 
O quadro 8 apresentou as respostas fornecidas à questão 6 , cujo objetivo estava relacionado à identificação dos conhecimentos dos acadêmicos sobre as forças fundamentais de interação que existem no Universo. O questionário inicial revela que os acadêmicos tinham conhecimentos prévios sobre o assunto. Entretanto, ele foi ampliado no decorrer do curso, qualificando as respostas no questionário final. As quatro interações fundamentais foram tema com presença significativa em todos os encontros, sendo mencionado em diversos momentos, o que, provavelmente, justifica o fato de os participantes apresentarem entendimento sobre ele. Ainda sobre essa questão, vale registrar que, em função das respostas do questionário inicial, no questionário final ela foi reformulada para um nível maior de dificuldade, de modo a captar novos conhecimentos.

Este ponto também foi tratado no terceiro encontro, quando foi analisada a idade da Terra. Antes de definir um conceito para a radioatividade, foi proposto verificar como ocorria a interação dentro do núcleo atômico. Novamente, foi mencionada a força nuclear forte como a responsável por manter o núcleo do átomo unido e foi introduzida a interação pelo mésons. Essas são as partículas responsáveis por transmitir a interação forte. Essa troca se dá somente no caso do núcleo, por prótons e nêutrons - especialmente, pelo mésons pi ou pion. Assim, utilizando as relações a partir do princípio da incerteza - em termos de energia-tempo, $(\Delta \mathrm{E} \Delta \mathrm{t}$ $\geq 1 / 2 \hbar)$ e equivalência massa-energia $\left(E=m^{2}\right)$-, procuramos evidenciar particularidades deste fenômeno. A conclusão foi que a interação do meśon pi tem alcance limitado e isso acarreta em uma instabilidade entre as forças forte e elétrica.

Esse aspecto foi mencionado no encontro como associado ao fato de que com o crescimento do núcleo atômico, é necessário mais elementos para manter a coesão nuclear. Dessa forma, em um núcleo muito grande a interação forte é inexistente com as partículas dos extremos. Tendo presença somente com partículas próximas. [...] um átomo grande enfileirado, as partículas dos extremos não interagem pelo meio da força forte, somente pela repulsão elétrica.

Nas respostas obtidas com o questionário final, identificamos alusões à "troca de partículas" e aos mésons pi, o que esteve vinculado ao encontro e foi descrito anteriormente. Também obtivemos respostas mais diretas, mas não incorretas, sobre o mesmo fenômeno.

A sétima questão de ambos os questionários e que está expressa no quadro 10 objetivou avaliar os conhecimentos dos licenciandos com relação à anã branca. As respostas apontam que os acadêmicos apresentavam algum conhecimento sobre o assunto. Porém, a partir das discussões do segundo encontro, quando analisamos a formação e a evolução estelar em função do seu fator principal - a massa -, podemos perceber que houve uma mudança nas respostas. No encontro, a sequência para a abordagem da formação e da evolução estelar ocorreu, inicialmente, a partir de uma nebulosa, passando pelo disco de acreção, a protoestrela e, por fim, a estrela em si. Para a evolução das estrelas, utilizamos o fator massa como componente principal e a massa do Sol como parâmetro. Assim, iniciamos com uma pequena porção de massa - objetos astronômicos com até $10 \%$ da massa do Sol - e aumentando 
gradativamente, isto é, entre $10 \%$ e $50 \%, 50 \%$, até oito vezes, de 8 até 25 vezes e, assim, sucessivamente. Dessa maneira, fomos desenvolvendo a produção de átomos em seu interior - os elementos formados - e o seu possível término de vida.

Quadro 9 - Questão 7 do questionário inicial e 1 do questionário final com as respectivas respostas.

\begin{tabular}{|c|c|}
\hline $\begin{array}{l}\text { QUESTIONÁRIO } \\
\text { INICIAL }\end{array}$ & RESPOSTAS \\
\hline $\begin{array}{l}\text { Qual é a definição de } \\
\text { uma "estrela anã } \\
\text { branca"? }\end{array}$ & $\begin{array}{l}\text { "Quando uma estrela de massa inferior a } 1 \text { massa solar colapsa, após a expansão, } \\
\text { ela se contrai e se condensa em uma esfera maciça, branca e pouco brilhante } \\
\text { composta de carbono submetida à uma pressão intensa"; "É o estágio final da vida } \\
\text { de algumas estrelas de massa intermediária"; "Seria como uma estrela de nêutrons, } \\
\text { que tem uma massaldensidade muito grande"; "Uma estrela pequena e fria"; "É o fim } \\
\text { de vida de uma estrela, ela é fria e pequena"; "Relativamente "pequena', } \\
\text { extremamente brilhante e relativamente 'fria."; Em branco (4). }\end{array}$ \\
\hline $\begin{array}{l}\text { QUESTIONÁRIO } \\
\text { FINAL }\end{array}$ & RESPOSTAS \\
\hline $\begin{array}{l}\text { Qual é o estágio final } \\
\text { do Sol? }\end{array}$ & $\begin{array}{l}\text { Anã Branca (5); "Após tornar-se uma gigante vermelha, o Sol se tornará uma } \\
\text { estrela anã branca e consumirá a energia até virar carvão"; "O Sol se tornará uma } \\
\text { gigante vermelha e após, uma anã vermelha"; Anã Preta (1); Anã Vermelha (1). }\end{array}$ \\
\hline
\end{tabular}

Fonte: dados da pesquisa, 2018.

Para tanto, a fim de evidenciar as características de uma anã branca, fora utilizada a equação de limite para a massa de uma anã branca, isto é, a massa de Chandrasekhar. Este limite é definido como a pressão máxima exercida pela gravidade que os elétrons em níveis de energia degenerados conseguem suportar. Tal fenômeno é decorrente dos efeitos quânticos - princípio da incerteza - e relativísticos - velocidades relativísticas. A equação mostra que o limite para a massa de uma anã branca é 1,44 massas solares. Também fornecemos um subsídio para a resposta do questionário final, definindo uma anã branca aquelas que são o fim de vida de uma estrela, aquele momento quando não consegue mais produzir energia nuclear. Contudo, por ser remanescente do núcleo de uma estrela, as anãs brancas possuem uma densidade e temperatura extremamente alta. Seu tamanho é semelhante à Terra, porém sua massa é equivalente à do Sol. Ainda que exista temperaturas e pressões altíssimas nestas estrelas, ainda não é o suficiente para dar início às fusões nucleares. O que resta para estas estrelas ao longo de milhares e até bilhares de anos é brilharem, devido a energia interna restante, e esfriarem até o ponto de se tornarem anãs pretas.

A relação do Sol com uma anã branca foi destacado como associada ao seguinte fato: Projeta-se o seu fim [Sol] para daqui a 4,5 bilhões de anos, quando se tornará uma gigante vermelha. A sua fase de gigante vermelha terá uma duração de aproximadamente de 100 
milhões de anos e depois desta fase, irá colapsar em uma supernova, formando uma nebulosa planetária com uma anã branca em seu centro, a qual poderá levar outros bilhões de anos até esfriar completamente.

Percebemos que, no questionário inicial, as respostas obtidas apresentam mais elementos para a definição de anã branca, como massa, tamanho, composição, embora quase a metade das respostas tenha sido em branco. No questionário final, prevaleceu um retorno mais direto, isto é, somente "anã branca", sem oferecer mais elementos.

Quadro 10 - Questão 7 do questionário final com as respostas.

\begin{tabular}{|c|c|}
\hline $\begin{array}{l}\text { QUESTIONÁRIO } \\
\text { INICIAL }\end{array}$ & RESPOSTAS \\
\hline $\begin{array}{l}\text { O que diferencia uma } \\
\text { estrela anã branca de uma } \\
\text { estrela de nêutrons? }\end{array}$ & $\begin{array}{l}\text { "A massa da estrela antes do colapso, sua composição final”; "Anã branca é o } \\
\text { estágio em que a estrela continua liberando energia"; "Seu tamanho"; "Seu } \\
\text { brilho, massa e densidade"; "A composição dela. A anã Branca é uma estrela } \\
\text { concisa e massiva. Já a de nêutrons é basicamente constituída de nêutrons"; } \\
\text { Massa (2); Em branco (2). }\end{array}$ \\
\hline
\end{tabular}

Fonte: dados da pesquisa, 2018.

O quadro 10 retrata a questão 7 do questionário final, que foi estruturada para investigar os conhecimentos dos participantes sobre o que diferencia uma anã branca de uma estrela de nêutrons, tema tratado no segundo encontro. Nela, apontamos para três aspectos que podemos utilizar para diferenciar um objeto de outro: massa, densidade e composição. Havendo diferença entre massa e densidade, consequentemente, a gravidade e o seu tamanho também serão influenciados. Tais explicações foram utilizadas nas respostas dos acadêmicos.

Quadro 11 - Questão 8 do questionário inicial e do questionário final com as respectivas respostas.

\begin{tabular}{|c|l|}
\hline \multicolumn{1}{|c|}{ QUESTIONÁRIO INICIAL } & \multicolumn{1}{|c|}{ RESPOSTAS } \\
\hline $\begin{array}{l}\text { Qual é o elemento químico de maior número atômico } \\
\text { natural? }\end{array}$ & $\begin{array}{l}\text { Urânio (3); Chumbo (1); “Número atômico 86, não } \\
\text { lembro o nome” (1); Prométio (1); Em branco (4). }\end{array}$ \\
\hline QUESTIONÁRIO FINAL & \multicolumn{1}{|c|}{ RESPOSTAS } \\
\hline $\begin{array}{l}\text { Qual é o elemento químico de menor número atômico } \\
\text { natural? }\end{array}$ & Hidrogênio (9) \\
\hline
\end{tabular}

Fonte: dados da pesquisa, 2018.

As respostas apresentadas no quadro 11 ilustram o questionamento sobre a identificação de um elemento químico por meio do número de prótons em seu núcleo, o que é 
identificado como "número atômico". A diferença na pergunta entre o primeiro e o segundo questionário reside no fato de que durante as atividades foi comentado a resposta, deste questionamento inicial, o que levou a diferenciá-la no segundo questionário. As respostas evidenciam que, no questionário inicial, essa informação não estava clara para todos os participantes, embora algumas respostas estivessem corretas. No questionário final, por sua vez, a pergunta foi diferenciada, envolvendo não mais o maior número atômico, mas o menor número atômico, cujas respostas foram iguais e corretas para todos os participantes. Podemos atribuir a mudança ao fato de ter mencionado o tema diversas vezes no curso. $\mathrm{O}$ urânio, por exemplo, foi mencionado no estudo da fissão nuclear e, consequentemente, na produção de energia. Em outro momento ele esteve presente no relato sobre a produção das bombas atômicas na Segunda Guerra Mundial.

Nesse encontro, foi mencionado que usando a ideia de bombardeamento por nêutron, Otto Hahn (1879-1968) e Fritz Strassman (1902-1980) realizaram a fissão do urânio em Berlin. O urânio 235, quando bombardeado com nêutrons, dava origem a núcleos de criptônio e bário. Muito mais leves que o urânio, o processo também libertava nêutrons.

O hidrogênio é o elemento mais simples e abundante do Universo e considerado o principal combustível nuclear, estando presente em todas as estrelas. Dentro das atividades realizadas, ele ganhou lugar de destaque quando abordamos a nucleossíntese primordial, a fusão termonuclear no interior das estrelas e discussões sobre a bomba de hidrogênio. Tais momentos podem ter sido significativos paras os acadêmicos, uma vez que, em sua totalidade, responderam que o hidrogênio é o elemento químico de menor número atômico natural.

Quadro 12 - Questão 9 do questionário inicial e do questionário final com as respectivas respostas.

\begin{tabular}{|l|l|}
\hline $\begin{array}{c}\text { QUESTIONÁRIO } \\
\text { INICIAL }\end{array}$ & \multicolumn{1}{|c|}{ RESPOSTAS } \\
\hline $\begin{array}{l}\text { Como é definido o } \\
\text { primeiro estágio de } \\
\text { vida de uma estrela? }\end{array}$ & $\begin{array}{l}\text { "Colapso gravitacional"; "A gravidade faz com que a massa de acumule, } \\
\text { aumentando a pressão e temperatura até que comece a ocorrer fusão nuclear"; "É } \\
\text { quando uma nuvem de poeira cósmica começa a se condensar e começa a criar o } \\
\text { campo gravitacional"; Nuvem de gases (1); Em branco (6). }\end{array}$ \\
\hline $\begin{array}{c}\text { QUESTIONÁRIO } \\
\text { FINAL }\end{array}$ & \multicolumn{1}{|c|}{ RESPOSTAS } \\
\hline $\begin{array}{l}\text { O que é o período } \\
\text { definido como } \\
\text { "Sequência } \\
\text { Principal"? }\end{array}$ & $\begin{array}{l}\text { "O periodo mais longo com as etapas da vida da estrela"; "Principais eventos } \\
\text { ocorridos no desenvolvimento do Universo"; "É o tempo para que um elemento } \\
\text { decaia numericamente atomico"; "Primeira meia-vida"; Não Sei (1); Em branco } \\
\text { (4). }\end{array}$ \\
\hline
\end{tabular}

Fonte: dados da pesquisa, 2018.

A questão 9, cujas respostas estão ilustradas no quadro 12, teve como objetivo verificar a compreensão sobre o principal período de vida de uma estrela. As respostas 
indicadas no quadro ilustram que os participantes tiveram dificuldade para entender esse tópico, pois ninguém obteve acerto no questionário final, a exemplo do ocorrido no inicial. No estudo da formação e evolução estelar, mencionamos que uma estrela nasce a partir do momento em que realiza fusões nucleares em seu interior. Todo o processo inicia de um desequilíbrio de forças em uma nebulosa, onde começa a aglutinação de matéria. Esta aglutinação de matéria é o que chamamos de "proto-estrelas", isto é, a matéria se concentra em um ponto e, por consequência, sua temperatura aumenta gradativamente. Este processo cessa quando inicia a fusão nuclear e ocorre o nascimento da estrela. Após este fenômeno, é estabelecido o período da "Sequência Principal", que foi explorado na proposta didática como o começo da fusão termonuclear em que é dado início à sequência principal. Agora a protoestrela já tem temperatura o suficiente para fundir hidrogênio em hélio, e com isso passa a ser uma estrela jovem. A sequência principal é o maior e principal período de uma estrela. É o momento quando a estrela atinge a capacidade de produzir fusões nucleares em seu núcleo, e termina quando a mesma não consegue mais fundir o hidrogênio em hélio.

Tais explicações se revelaram insuficientes para a compreensão dos participantes, que forneceram respostas como "não sei” ou não responderam.

Quadro 13 - Questão 10 do questionário inicial e do questionário final com as respectivas respostas.

\begin{tabular}{|c|c|}
\hline $\begin{array}{l}\text { QUESTIONÁRIO } \\
\text { INICIAL }\end{array}$ & RESPOSTAS \\
\hline $\begin{array}{l}\text { O que diferencia um } \\
\text { planeta telúrico de um } \\
\text { joviano? }\end{array}$ & $\begin{array}{l}\text { "Sua temperatura e cor"; "Um planeta é sólido e outro gasoso"; "A distância do } \\
\text { Sol e componentes que esses planetas são formados"; "O tempo de formação"; "A } \\
\text { idade de formação dele"; "Telúrio tem luas, joviano não"; Idade (1); Em branco } \\
\text { (3). }\end{array}$ \\
\hline $\begin{array}{l}\text { QUESTIONÁRIO } \\
\text { FINAL }\end{array}$ & RESPOSTAS \\
\hline $\begin{array}{l}\text { Por quais argumentos } \\
\text { podemos definir um } \\
\text { objeto astronômico } \\
\text { como um planeta? }\end{array}$ & $\begin{array}{l}\text { "Órbita plana em relação a uma ou mais estrelas"; "Pela sua órbita em relação ao } \\
\text { sistema solar"; "Ter uma órbita e um tamanho razoável"; "Tamanho, órbita, } \\
\text { distância da estrela que orbita"; "Este ser influenciado pelo campo de uma estrela e } \\
\text { possuir um campo gravitacional capaz de influenciar objetos próximos"; Não sei } \\
\text { (1); Em branco (3). }\end{array}$ \\
\hline
\end{tabular}

Fonte: dados da pesquisa, 2018.

Podemos diferenciar um planeta telúrico de um joviano por sua composição. Formulando de outra maneira, seria como perguntar: "Qual a diferença de um planeta rochoso e de um gasoso?". O uso dos termos "telúrico" e "joviano" foram diferentes dos utilizados no curso para verificar se os acadêmicos eram capazes de estabelecer relações com o que foi abordado nos encontros. Um planeta telúrico pode ser definido como aquele que tem 
composição rochosa, enquanto um planeta joviano é gasoso. No caso do Sistema Solar, o gradiente de temperatura a partir do Sol tem influência e, decorrente disso, temos os planetas rochosos - como os quatros primeiros -, que estão mais perto do centro, do que os planetas gasosos - os quatro últimos.

As respostas ilustradas no quadro 13 e obtidas com o questionário inicial indicam apenas uma correta. Entretanto, no questionário final, obtivemos nas respostas aquilo que foi debatido no encontro, variando comente em quantidade de elementos.

O tema foi tratado no terceiro encontro, no mês de setembro no CC, momento em que iniciamos a discussão sobre o Sistema Solar. Definimos o entendimento de "planeta" a partir de pontos como o tamanho do planeta, distância dele, objeto até a estrela, influência gravitacional e a órbita estando no mesmo plano dos demais.

Quadro 14 - Questão 11 do questionário inicial e do questionário final com as respectivas respostas.

\begin{tabular}{|c|c|}
\hline $\begin{array}{l}\text { QUESTIONÁRIO } \\
\text { INICIAL }\end{array}$ & RESPOSTAS \\
\hline $\begin{array}{l}\text { A datação por } \\
\text { elementos radioativos } \\
\text { permite a estimativa } \\
\text { de conhecer uma } \\
\text { passagem de tempo, } \\
\text { como este processo é } \\
\text { realizado? }\end{array}$ & $\begin{array}{l}\text { "Por meio da datação de meia-vida de um elemento"; "A partir do decaimento } \\
\text { atômico do átomo é possivel determinar a sua idade aproximada"; "Sabe-se que } \\
\text { existem elementos radioativos a uma taxa constante, assim observando a proporção } \\
\text { existente em um material e comparando com a meia vida da 'substancia', é possivel } \\
\text { saber a quanto tempo começou a decair"; "Ele é medido pelo decaimento radioativo } \\
\text { e conforme o tempo passa, o nivel radioativo vai caindo"; "Indicativa da } \\
\text { decomposição dos materiais radioativos, no material estudado"; "Sabendo-se a } \\
\text { meia vida, pode-se determinar o número de vezes que ocorreram fissões e então } \\
\text { calcular o periodo de tempo; Em branco (4). }\end{array}$ \\
\hline $\begin{array}{c}\text { QUESTIONÁRIO } \\
\text { FINAL }\end{array}$ & RESPOSTAS \\
\hline $\begin{array}{l}\text { Como se pode medir a } \\
\text { passagem do tempo } \\
\text { usando a } \\
\text { radioatividade? }\end{array}$ & $\begin{array}{l}\text { "Pelo decaimento atômico de um elemento"; "Sabendo-se a meia vida de cada } \\
\text { elemento"; "Através da meia-vida e decaimentos"; "Através de seu decaimento", } \\
\text { "Através da declividade da radiação"; "Pelo decaimento do elemento radioativo"; } \\
\text { "Através do cálculo de decaimento da meia vida de um material. Basta saber o } \\
\text { tempo de decaimento e a massa da amostra; Não sei (1); Em branco (1). }\end{array}$ \\
\hline
\end{tabular}

Fonte: dados da pesquisa, 2018.

As questões apresentadas nos questionários inicial e final e expressas no quadro 14 apresentam objetivo e contextos similares, relacionado à identificação dos conhecimentos sobre radioatividade. $\mathrm{O}$ intuito estava em apresentar às participantes situações distintas e diferenciar ao final do abordado durante os encontros. As respostas revelaram que os participantes apresentaram os mesmos elementos nos questionários inicial e final. Somente uma resposta foi satisfatória entre os dois testes. Tal resposta correta se apresenta no questionário final e assinala dois elementos: a meia-vida e a massa da amostra. $\mathrm{O}$ resto das respostas carece de informações, sendo incompletas ou equivocadas. 
Um dos tópicos discutidos nos encontros foi que a estimativa de passagem do tempo por meio da radioatividade se faz pelo conhecimento da meia-vida do material usado e a contagem das porções relativas do elemento-pai e o elemento-filho, isto é, a quantidade de matéria original e a quantidade de matéria derivada do processo. Um exemplo pode ser o urânio que, sabendo o tempo de meia-vida do urânio e o seu produto final, basta uma mera comparação entre as quantidades de U-238 e o Pb-206 para definirmos a idade do material.

Quadro 25 - Questão 12 do questionário inicial e do questionário final com as respectivas respostas.

\begin{tabular}{|c|c|}
\hline $\begin{array}{l}\text { QUESTIONÁRIO } \\
\text { INICIAL }\end{array}$ & RESPOSTAS \\
\hline $\begin{array}{l}\text { Qual é o fator } \\
\text { determinante para a } \\
\text { vida de uma estrela } \\
\text { (cor, temperatura, vida, } \\
\text { e etc.)? }\end{array}$ & $\begin{array}{l}\text { "O elemento que entra em fusão majoritariamente"; "A quantidade de matéria } \\
\text { envolvida no colapso gravitacional e os elementos presentes"; "Principalmente a } \\
\text { massa, mas também os elementos químicos que a compõem"; "Os elementos } \\
\text { químicos dos quais as estrelas são formadas"; Intensidade luminosa (1); } \\
\text { Temperatura (3); Composição (2); Tamanho (1);Em branco (3). }\end{array}$ \\
\hline $\begin{array}{l}\text { QUESTIONÁRIO } \\
\text { FINAL }\end{array}$ & RESPOSTAS \\
\hline $\begin{array}{l}\text { Sabendo a massa de } \\
\text { uma estrela, quais } \\
\text { características podemos } \\
\text { determinar? }\end{array}$ & $\begin{array}{l}\text { "Seu tempo de vida e sua gravidade"; "Idade, elementos que ela funde, tamanho", } \\
\text { "Ocorre fusão no centro, e mas demora para liberar os elementos por causa da } \\
\text { densidade"; "Cor, tamanho, tempo de vida"; "Idade, tempo de vida, tipo"; "Cor, } \\
\text { temperatura, tamanho, tipos de elementos"; "Elementos, luminosidade, cor, } \\
\text { densidade, atração gravitacional"; "Sabendo a massa é possivel determinar a } \\
\text { tempo restante de vida da estrela, caso se saiba a composição"; Em branco (1). }\end{array}$ \\
\hline
\end{tabular}

Fonte: dados da pesquisa, 2018.

A questão 12, no quadro 15, apresentada no questionário inicial e final, foi organizada para verificar se os acadêmicos eram capazes de identificar o que determina a vida de uma estrela. As respostas permitem identificar que, no questionário final, foram mencionados vários elementos como resposta, diferentemente do inicial, quando somente duas das respostas foram satisfatórias. Tal situação evidencia que os participantes estiveram envolvidos com o tema.

O tema foi amplamente discutido no segundo encontro, a partir de aspectos como: Se tomamos o nosso Sol como referência de massa e analisarmos algumas estrelas, vamos notar que, não somente a massa influencia na questão do tempo de vida, mas também no seu desfecho, envolvendo temperatura e brilho. De acordo com a sua massa podemos definir o seu futuro se tornando uma estrela anã branca, um buraco negro ou uma estrela de nêutron. Da mesma maneira, o brilho e a temperatura de uma estrela também será definido pela sua massa, uma vez que os corpos estelares mais massivos são mais quentes e luminosos (cores branca, azul), enquanto as menores são mais frias e menos luminosas (cores vermelho, laranja). 
A questão, no primeiro momento, é formulada em um sentido, enquanto, no segundo, o seu sentido é invertido. Se faz importante perceber que tanto a questão do questionário inicial quanto a do questionário final tem um fator em pauta: a massa. De mesmo modo, podemos remeter a outras questões, como a um e a sete do questionário final e a sete do inicial, que envolvem a mesma pauta.

Quadro 36 - Questão 13 do questionário inicial e do questionário final com as respectivas respostas.

\begin{tabular}{|c|c|}
\hline $\begin{array}{l}\text { QUESTIONÁRIO } \\
\text { INICIAL }\end{array}$ & RESPOSTAS \\
\hline $\begin{array}{l}\text { Elementos químicos } \\
\text { com um número } \\
\text { atômico muito alto } \\
\text { comumente são } \\
\text { elementos radioativos, } \\
\text { qual é a explicação para } \\
\text { isso? }\end{array}$ & $\begin{array}{l}\text { "Devido a sua instabilidade para manter seu número atômico"; "A estabilidade do } \\
\text { átomo devido ao seu tamanho"; "A força necessária para manter esses átomos } \\
\text { estáveis seria muito grande"; "São instáveis (com meia-vida) e acabam por liberar } \\
\text { energia radioativa quando se transformam"; "Por ele ter uma vida mais curta, por } \\
\text { ser um grande emissor de partículas e ser instável"; "Por possuírem maior carga, } \\
\text { é mais provável a quebra de suas subpartículas"; Núcleo instável (1). Em branco } \\
\text { (4). }\end{array}$ \\
\hline $\begin{array}{l}\text { QUESTIONÁRIO } \\
\text { FINAL }\end{array}$ & RESPOSTAS \\
\hline $\begin{array}{l}\text { Qual é a explicação } \\
\text { para que elementos } \\
\text { pesados apresentaram } \\
\text { características } \\
\text { radioativas? }\end{array}$ & $\begin{array}{l}\text { "A instabilidade do núcleo"; "Ficam muito pesados, precisando de um alto nível } \\
\text { de energia para se manter"; "Interação nuclear mais instável"; "Pois são mais } \\
\text { instáveis"; "Possuem núcleos muito grandes"; Em branco (3). }\end{array}$ \\
\hline
\end{tabular}

Fonte: dados da pesquisa, 2018.

O quadro 16 exibe a pergunta do questionário inicial e final, que foram as mesmas, se diferenciando apenas na formulação. O objetivo era averiguar se os licenciandos apresentavam conhecimentos antes e depois da intervenção relacionadas à instabilidade nuclear. Tal ponto seria abordado no terceiro encontro, quando foi explicitada a idade da Terra.

O tema que também foi abordado na questão 6 do questionário inicial e 5 do questionário final, como exemplificado no quadro 6 , obteve como resposta que os elementos químicos pesados apresentem características radiativas, centrando-se na instabilidade do núcleo e no seu tamanho. Além disso, observamos pouca evolução nas respostas entre os dois questionários. 
Quadro 17 - Questão 14 do questionário inicial e do questionário final com as respectivas respostas.

\begin{tabular}{|c|l|}
\hline $\begin{array}{c}\text { QUESTIONÁRIO } \\
\text { INICIAL }\end{array}$ & \multicolumn{1}{|c|}{ RESPOSTAS } \\
\hline $\begin{array}{l}\text { Explique o conceito de } \\
\text { meia-vida. }\end{array}$ & $\begin{array}{l}\text { "É o tempo necessário para o número atômico de um elemento cair pela metade"; } \\
\text { "Tempo para que um quantum de determinado elementos decaia sua massa pela } \\
\text { metade"; "Depende do seu decaimento radioativo"; "O tempo que uma } \\
\text { determinada massa demora para decair a metade dessa massa"; "São referentes a } \\
\text { duração de alguns elementos radioativo"; "Duração de vida de um átomo"; "É a } \\
\text { metade de vida de uma estrela"; "Tempo que o elemento radioativo leva para } \\
\text { decompor"; "Meia vida é o periodo para que ocorra a fissão"; Em branco (2). }\end{array}$ \\
\hline $\begin{array}{c}\text { QUESTIONÁRIO } \\
\text { FINAL }\end{array}$ & \multicolumn{1}{|c|}{ RESPOSTAS } \\
\hline $\begin{array}{l}\text { Durante quanto tempo } \\
\text { um elemento se } \\
\text { mantém radioativo? }\end{array}$ & $\begin{array}{l}\text { "Enquanto estiver instável"; "Até o núcleo estabilizar"; "Até decair"; "Até que } \\
\text { haja um decaimento suficiente"; "Até formar um núcleo estável"; "Durante seu } \\
\text { periodo de meia-vida"; Em branco (2). }\end{array}$ \\
\hline
\end{tabular}

Fonte: dados da pesquisa, 2018.

O tema abordado nessa questão, expressa no quadro 17, era relacionado à "meiavida", cujo conceito aparece como importante em se tratando do estudo da radioatividade. $\mathrm{O}$ termo é m aplicado para definir o tempo que a metade de uma porção de matéria se transmuta em outra.

Nos encontros, o tema foi abordado da seguinte forma: Podemos utilizar o exemplo do C-14 (isótopo mais usado para a datação de compostos orgânicos) onde a sua meia-vida é de, aproximadamente, 5000 anos. Isto significa que em 5000 anos, um quilograma de C-14 terá transmutado em 500 gramas em N-14. Estes 500 gramas restantes de carbono levaram mais 5000 anos para que 250 gramas se transformem em nitrogênio e assim sucessivamente. Desta forma, a cada meia-vida de um elemento, a sua atividade radioativa se reduz à metade da anterior até que atinja valores insignificantes que, de tão pequenos não possam ser percebidos.

Analisando as respostas tanto no questionário inicial como no final, identificamos que elas foram incompletas e pouco satisfatórias. No questionário final, por exemplo, observamos que nenhum dos acadêmicos abordou de forma completa o tempo que um elemento se mantém radioativo. 
Quadro 18 - Questão 15 do questionário inicial e do questionário final com as respectivas respostas.

\begin{tabular}{|c|c|}
\hline $\begin{array}{l}\text { QUESTIONÁRIO } \\
\text { INICIAL }\end{array}$ & RESPOSTAS \\
\hline $\begin{array}{l}\text { Aponte uma área onde } \\
\text { necessite dos } \\
\text { conhecimentos da Física } \\
\text { Nuclear e como ele é } \\
\text { utilizado. }\end{array}$ & $\begin{array}{l}\text { Engenharia Nuclear (1); Medicina (3); Engenharia Física (1); Física Médica (1); } \\
\text { Astronomia (1); Engenharia Química (1); Usinas Nucleares (2); Tomografia (1); } \\
\text { Radioterapia (1); "Energia" (3); Fissão Nuclear (2). }\end{array}$ \\
\hline $\begin{array}{l}\text { QUESTIONÁRIO } \\
\text { FINAL }\end{array}$ & RESPOSTAS \\
\hline $\begin{array}{l}\text { Quais são os cuidados } \\
\text { que se deve ter quando } \\
\text { existe a exposição à } \\
\text { radiação? }\end{array}$ & $\begin{array}{l}\text { "Lavar as mãos, olhos, não ter contato com a boca e ir em um médico"; "Usar } \\
\text { luvas e equipamentos de proteção, com materiais que bloqueiam a passados dos } \\
\text { raios gama, radioativos"; "Usar roupas e equipamentos adequados para que não } \\
\text { ocorra contaminação"; "Todos os possiveis"; "Chamas as autoridades } \\
\text { responsáveis, não mexer e se afastar"; "Não se expor por muito tempo, evitar } \\
\text { exposiçãa direta, não ingerir"; "Proteger-se com roupas adequadas e não } \\
\text { encostar"; Em branco (2). }\end{array}$ \\
\hline
\end{tabular}

Fonte: dados da pesquisa, 2018.

Nesse último questionamento, ilustrado no quadro 18, que foi, de certa forma, equivalente nos dois questionários tivemos o objetivo de verificar se os acadêmicos tinham ampliado seus conhecimentos sobre a presença e importância dos conhecimentos de FN na vida das pessoas e, por consequência, os cuidados que devemos ter com ela. As respostas obtidas permitem inferir que, no questionário inicial, os acadêmicos apontaram, com respostas curtas e diretas, diversas áreas que julgavam envolver ou necessitar de conhecimentos de FN. No questionário final por sua vez, identificamos que eles foram mais abrangentes e capazes de citar cuidados que são necessários quando uma pessoa é exposta à radiação.

Situações de risco envolvendo radiação foram um dos aspectos explorados nos encontros, como provenientes da radiação em organismos biológicos no começo do século $\mathrm{XX}$ ainda eram desconhecidos e por isso, não havia precaução alguma. Contém vários relatos de mortes devido à manipulação de elementos radioativos que na época eram ignorados. No corpo humano podem ocorrer lesões, leves ou mais graves, dependendo da intensidade da radiação. Essas lesões podem ocorrer na pele ou em órgãos internos do corpo. Com grande energia, a radiação é capaz de destruir as moléculas que compõem esses órgãos.

Além disso, os cuidados também foram mencionados ao relatar o acidente radiológico com o Cs-137, cujos reflexos ainda são sentidos, mesmo após mais de 30 anos. 


\section{Considerações finais}

O presente estudo buscou analisar a pertinência de uma proposta didática que toma o CC como suporte contextualizador dos conteúdos de FN presente no ensino médio. A relevância da proposta surge frente às necessidades de qualificar a apropriação dos conceitos da área da FN e de possibilitar uma abordagem didática de forma contextualizada e instigante. A importância dos conteúdos contemplados na proposta reside na sua presença no cotidiano das pessoas e por agregarem um corpo de conhecimentos que tem sido pouco explorado na escola.

O intuito de utilizar o CC foi de representar a idade do Universo, em sua totalidade, na forma de um calendário, cujas discussões começam com o Big Bang, em primeiro de janeiro, e terminam na atualidade, 31 de dezembro.

A operacionalização da proposta ocorreu junto a um grupo de professores em formação inicial e foi desenvolvida na forma de um curso de extensão. A aplicação da proposta didática foi permeada por discussões e uma constante interlocução dos acadêmicos com o pesquisador, mostrando o interesse pelo tema e, ao mesmo, tempo revelando que, para muitos deles, esse representava um dos primeiros momentos de contato com a temática. A aplicação da proposta didática foi permeada por discussões e uma constante interlocução dos acadêmicos com o pesquisador, mostrando o interesse pelo tema e, ao mesmo tempo revelando que, para muitos deles, esse representava um dos primeiros momentos de contato com a temática.

As respostas dadas aos questionários inicial e final elucidaram que poucos deles tinham tido contato com a FN durante sua formação na Educação Básica ou mesmo no início da graduação. Todavia, havia aqueles que, por conta própria ou levados por outras disciplinas curriculares, apresentavam algum conhecimento sobre o assunto. Ainda sobre a análise dos questionários, relatamos que foi possível averiguar uma evolução nos conhecimentos dos acadêmicos como decorrência das atividades desenvolvidas, particularmente as relacionadas a discussões que estiveram presente nos encontros. Essa aparente e identificada evolução nos conhecimentos ocorreu de forma a respeitar a individualidade de cada um, seus conhecimentos prévios e sua estruturação cognitiva. O que foi possível perceber é que ela foi mais significativa para uns do que para outros. Evidentemente, isso também está relacionado aos conhecimentos prévios, uma vez que alguns já haviam tido contato com o tema, conforme mencionado anteriormente. Outro detalhe levantado pelos questionários foi o espaço informal oportunizado pelo curso e que possivelmente tenha influência nas respostas do questionário, uma vez que os participantes não tinham uma "responsabilidade por uma nota boa". Dentro disto, as respostas obtidas nos questionários deram a exposição de uma dificuldade de escrita pelos estudantes. Isto fica visível nas respostas curtas e pouco elaboradas.

Por fim, destacamos que frente a pergunta de pesquisa - qual a viabilidade de uma proposta didática que toma o Calendário Cósmico como suporte de contextualização dos conteúdos de Física Nuclear presente no ensino médio? - julgamos que a proposta 
desenvolvida se mostrou viável didaticamente e possível de contribuir para que os estudantes ampliem seus conhecimentos no campo da FN.

\section{Referências}

BRASIL. Ministério da Educação. Base Nacional Comum Curricular - Ensino Médio. 2018.

BRASIL. Ministério da Educação. Parâmetros Curriculares Nacionais $+(\mathrm{PCN}+)$ Ensino Médio: orientações educacionais complementares aos Parâmetros Curriculares Nacionais: ciências da natureza, matemática e suas tecnologias. Brasília: Ministério da Educação, Secretaria de Educação Básica, 2002.

GLEISER, M. Poeira das estrelas. Textos de apoio Frederico Neves. São Paulo: Globo. 2006.

GONÇALVES, O. D.; ALMEIDA, I. P. S. A energia nuclear. Ciência Hoje, v. 37, n. 220, p. 36-44, 2005.

OLIVEIRA FILHO, K. de S.; SARAIVA, M. de F. O. Astronomia e Astrofísica. 3. ed. São Paulo: Editora Livraria da Física, 2014.

ROSA, C. T. W. da. Laboratório didático de Física da Universidade de Passo Fundo: concepções teórico-metodológicas. 2001. Dissertação (Mestrado em Educação) Universidade de Passo Fundo, Passo Fundo.

SOUZA, M. A. M. de; DANTAS, J. J. Fenomenologia nuclear: uma proposta conceitual para o ensino médio Caderno Brasileiro de Ensino de Física, v. 27, n. 1, p. 136-158, 2010.

SOUZA, R. S. de. Uma sequência didática para o ensino de Física Nuclear no Ensino Médio. 2018. Dissertação (Mestrado em Ensino de Física) - Programa de Mestrado Profissional em Ensino de Física, Sociedade Brasileira de Física, Universidade Federal de Juiz Fora, Juiz de Fora, MG.

TRIVIÑOS, A. N. S. Introdução à pesquisa em ciências sociais: a pesquisa qualitativa em educação. São Paulo: Atlas, 1987.

(cc) BY-NC-ND Direito autoral e licença de uso: Este artigo está licenciado sob uma Licença Creative Commons 